\title{
The Quality of Life of Young Old (YOLD) Elders in Elderly Clubs in Jakarta
}

\author{
Pamela Hendra Heng ${ }^{1 *}$ Riana Sahrani ${ }^{1}$ Christy Christy ${ }^{1}$ \\ ${ }^{1}$ Faculty of Psychology, Universitas Tarumanagara, West Jakarta, 11440, Indonesia \\ "Corresponding author. Email: pamelah@fpsi.untar.ac.id
}

\begin{abstract}
Early in 2020, the term YOLD, namely "Young Old", is an elder between the ages of 65 and 75 who still has the characteristics of a young person. Declining conditions in some aspects need to be adjusted by elders to avoid feeling useless, excluded, lonely or prone to disease. However, if they have a positive outlook and realize that their experiences and wisdom can be role models for the next generation, they can have a good quality of life. Quality of life is an individual's view of their position in life, in their culture or value system, related to expectations, interests, and achievements. This study aims to describe the quality of life of YOLD joining elderly clubs in Jakarta. The YOLD measuring instrument used is the Indonesian version of the WHOQOL-BREF which is a Likert scale consisting of 26 items. The number of participants in this study were 66 elders. The results of this study indicate that the elders' quality of life has differences in terms of the need for assistance and hope. Elders who feel they have enough activities have a higher quality of life than elders who want to have more activities.
\end{abstract}

Keywords: YOLD, quality of life, WHOQOL-BREF, elders, elderly club

\section{INTRODUCTION}

The positive impact of successful development on all aspects of human life can be enjoyed by the improvement of good health services, education services and social services. The rapid advances in medicine have had a major impact on the health of the population. This can be seen from the increase in the average age of life expectancy, especially in countries with high levels of welfare such as: The Netherlands, Japan, the United States, Canada, Australia, Sweden, etc.

Given that whoever is a human being in this world, if there are no accidents, natural disasters or things beyond human control that have fatal consequences, then everything will lead to old age. Many things are of interest and require serious attention about this aging population. Indeed, old age has decreased on the physical side, but the experience and wisdom that is very meaningful is in those who can become role models for the younger ones. The attention of various parties including the government, which is obliged to participate in the welfare of all residents, needs to be increased because this elderly group can become an economic and social burden if it is not maximally empowered [1]

Recently, a WhatsApp (WA) message went viral in many WA groups stating how life always moves and changes unexpectedly, with a new interesting term or acronym, YOLD, short for "Young Old". The term is for those aged 65 to 75 years who still have the characteristics of young people. They are the generation of the postWorld War-II "baby boomer" period (1946-1965), which are expected to be in their retirement years by now. However, the reality is not as expected as these baby boomers continue to work and remain socially engaged, while their population increases, are healthier and richer than the previous generations of elderly citizens. With a baby boomer population reaching 134 million in developed countries this year, 2020 will mark the beginning of the "YOLD" decade. YOLD is against declining health. According to WHO, in developed countries between 2000-2015 they had a 3.7 years increase in life expectancy and 3.2 years enjoyed in "good health". The trend for YOLDs to continue working has increased rapidly since 2016 , with more than a fifth of people aged 65-69 are still working in developed countries (Evalina, January 20, 2020, communication in WA group of Faculty of Medical Sciences).

A study in Germany states that the passion to continue to exist and work is what helps baby boomers stay strong. This study shows that people who continue to work after retirement age can slow down the decline in intellectual / cognitive potential that usually occurs in older people. Yold's revival turned out to be quite influential on the consumer, service and financial markets. For example, they changed the Education sector. At this time, Harvard had more students in the Division for Continuing Education than at the university itself. This division is focused on adult and retired students who wish to continue their Education at a later stage of their life [2]. 
Yold also challenged pre-existing social norms. "While many bosses and Human Resource departments think productivity declines with age, a study at a trucking factory and insurance company in Germany shows that older workers have at least slightly above average productivity and that teams of workers of different generations are the most productive of all, "reports The Economist". Meanwhile, society will also be better off with Yold not retiring, as public spending on health and pensions will remain much lower than expected, as people who continue to work will need relatively less medical care [2].

Yold, who remains active, also contributes to the global economy as a whole. According to the Economist, those who are now over 60 s are one of the rapidly expanding customer groups in the aviation and tourism industry because they spend more time traveling abroad, compared to younger people [2].

The baby boomers (YOLD), may be able to change the world, as they have done several times before at various stages of their lives [2]. It turns out that "experience is the best teacher," because it teaches not only about studying longer and more but also about seeing, analyzing, planning, implementing and judging better and wisely. The conclusion is to live healthier and happier, the elderly must continue to roam around, hang out, stay stylish and active, learn and develop themselves in order to remain useful for the environment, family or at least for themselves. Ageing is a privilege. You are never too old to set another goal or to dream another dream (Lewis in Evalina, January 19, 2020, communication in WA group of Faculty of Medical Sciences).

In Indonesia, matters concerning Manpower are regulated in the Law of the Republic of Indonesia Number 13 of 1998. Article 1 paragraph 2 states that a person referred to as an elderly person is a person aged 60 years and over. In the next paragraph, paragraph 3 states that a potential elderly person is an elderly person who is still capable of doing work and / or activities that can produce goods and / or services. Furthermore, in verse 4 it is said that the elderly with no potential are those who are powerless to earn a living, so they depend on the help of others. Article 5 paragraph 1 and article 6 paragraph 1 states the same rights and obligations of elderly people in the life of society, nation and state (LN. 1998 / No.190, TLN NO. 3796, LL SETNEG: 16 HLM)

Some of the problems commonly faced by elderly people are the decline in physiological, psychological, physical and economic aspects where this is directly or indirectly related to motor, cognitive, emotional, interest, social, economic and religious sensory decline. This condition requires good adjustments so that YOLDs can accept reality to avoid stress, have low self-esteem, feel useless, marginalized, lonely or susceptible to disease but become YOLD who have a positive view that old age is a time of opportunity to develop, showing themselves as people who are active and involved in social activities, which will determine a good quality of life and people who are able to realize the meaning of life.
The quality of life in question is included in the definition of quality of life put forward by Tonon [3], namely the quality of life is an individual's view of their life position, in the culture or value system they adhere to, relating to expectations, interests, and achievements. However, The WHOQOL Group [4] also says that the quality of life is subjective to everyone, from a positive and negative perspective, and is a multidimensional concept. Research on the quality of life of the elderly, especially the young elderly, has not been widely studied, especially in Indonesia. Based on the description above, the researcher wants to know the description of the Quality of Life of the Young and Old (YOLD) of the elderly in the elderly club / group in Jakarta.

\section{BACKGROUND}

\subsection{Statement of Problems}

Problems that are generally faced by elders are declining physiological, psychological, physical and economic aspects which are related directly or indirectly to decreased motor-sensory, cognitive, emotional, interest, social, economic and religiosity. This condition requires good adjustments so that YOLDs can accept reality to avoid stress, low self-esteem, feel useless, be left out, lonely or susceptible to disease, and instead become YOLDs who have a positive view of old age as being an opportunity to develop, proving themselves to be active and be involved in social activities; which determines a good quality of life and an ability to realize the meaning of life.

The quality of life in question is included in the definition of quality of life put forward by Tonon [3], namely an individual's view of their position in life, in the culture or value system they adhere to, that are related to expectations, interests and achievements. However, the WHOQOL Group [4] also states that the quality of life is subjective to everyone, from a positive and negative perspective, and is a multidimensional concept. Research on the quality of life of the elderly, especially young elderly, has not been widely studied, especially in Indonesia. Based on the description above, the researcher wants to know an overview of the quality of life of the young old (YOLD) elders joining in elderly clubs or groups in Jakarta.

\section{METHODS}

The design of this research is a non-experimental quantitative, using a measuring instrument in the form of a questionnaire. This research has received ethical approval with an approval number of PPZ20192068 from Universitas Tarumanagara, Human Research Ethics Committee, Institution of Research and Community Engagement. The total number of subjects was 100 participants aged 65-75 years, domicile was not limited. However, only 66 subjects were able to be processed as 
data. Dissemination of questionnaires were done online, because during this pandemic COVID-19, it is not possible to be given out directly. Data collection was carried out by distributing two kinds of questionnaires to participants. This research consisted of two steps. First, the researchers asked the club administrator for help to collect and sort out questionnaires to YOLDs in the club who meet the criteria outlined in the research. Second, the researchers created a demographic questionnaire and distribute the quality of life questionnaire to the YOLDs through their club administrator.

The research instruments used are of two types. The first instrument is used to collect YOLD data from club administrators, in the form of simple questions about the identity of club participants, especially regarding the participants' age and physical, mental, psychosocial and economic conditions. In the second instrument, YOLD was asked questions about quality of life using the Indonesian version of the WHOQOL-BREF developed by Purba et al. [5]. The measuring instrument consists of 26 items, with two of them measuring the overall quality of life and general health conditions of the participants. The other 24 items are divided into four dimensions, namely the physical, psychological, social relations and environmental dimensions. The Indonesian version of the WHOQOL-BREF uses five Likert scale options, ranging from very bad (score of 1 ) to very good (score of 5 ).

\section{FINDINGS AND DISCUSSIONS}

In this study, Participants who were male were 30 people with a percentage of $45.5 \%$ and participants who were female were 36 people with a percentage of $54.5 \%$.

Table 1 Participants based on gender

\begin{tabular}{lll}
\hline Gender & Frequency & Percent \\
\hline Male & 30 & 45.5 \\
Female & 36 & 54.5 \\
\hline Total & 66 & 100 \\
\hline
\end{tabular}

Participants who were in the 65-70 years category were 47 people with a percentage of $71.2 \%$ and 19 participants at the age $71-75$ years with a percentage of $28.8 \%$.

Table 2 Participants based on age

\begin{tabular}{lll}
\hline Age & Frequency & Percent \\
\hline $65-70$ & 47 & 71.2 \\
$71-75$ & 19 & 28.8 \\
\hline Total & 66 & 100 \\
\hline
\end{tabular}

Most of the elders in this study completed junior high school were 27 people with percentage $40.9 \%$, followed by elders with an education background of senior high school were 24 people with percentage $36.4 \%$ and of primary school were 12 people with percentage $18.2 \%$. Whereas elders who earned a diploma, a bachelor's or a master's degree are 1 people with percentage $1.5 \%$ of the study's participants.
Table 3 Participants based on education

\begin{tabular}{lcc}
\hline Education & Frequency & Percent \\
\hline Primary school & 12 & 18.2 \\
Junior high & 27 & 40.9 \\
school & & \\
Senior high & 24 & 36.4 \\
school & & \\
Diploma & 1 & 1.5 \\
Bachelor's & 1 & 1.5 \\
degree & & \\
Master's Degree & 1 & 1.5 \\
\hline Total & 66 & 100 \\
\hline
\end{tabular}

The majority of the participants are people of Chinese ethnicity were 38 people with percentage $57.6 \%$, followed by participants of Javanese ethnicity were 19 people with percentage $28.8 \%$, Sundanese ethnicity were 7 people with percentage $10.6 \%$, Betawi people were 1 people with percentage $1.5 \%$ and Flores people were 1 people with percentage $1.5 \%$.

Table 4 Participants based on ethnicity

\begin{tabular}{lcc}
\hline Ethnicity & Frequency & Percent \\
\hline Betawi & 1 & 1.5 \\
Flores & 1 & 1.5 \\
Javanese & 19 & 28.8 \\
Sundanese & 7 & 10.6 \\
Chinese & 38 & 57.6 \\
\hline Total & 66 & 100 \\
\hline
\end{tabular}

The income and expenses of the elders are mostly below IDR 5 million were 64 people with percentage $97 \%$, with a few earning between IDR $5-10$ million were 2 people with percentage $3 \%$.

Table 5 Participants based on income

\begin{tabular}{lccc}
\hline Income & Frequency & Percent \\
\hline $\begin{array}{l}\text { Below } \\
\text { million }\end{array}$ & 5 & 64 & 97 \\
IDR 5-10 million & 2 & 3 \\
\hline Total & 66 & 100 \\
\hline
\end{tabular}

A majority of the seniors or elders who take part in elderly clubs generally have only joined the club for less than 1 year were 35 people with percentage $53 \%$, joined for 1-3 years were 17 peaple with percentage $25 \%$ have and have joined for 3 years were 14 people with percentage $21.2 \%$.

Table 6 Participants based on joined the clubs

\begin{tabular}{lrc}
\hline Joined the clubs & Frequency & Percent \\
\hline < than 1 year & 35 & 53.0 \\
1-3 years & 17 & 25.8 \\
>than 3 years & 14 & 21.2 \\
\hline Total & 66 & 100 \\
\hline
\end{tabular}

Out of all the activities offered in the clubs, physical activity exceeds other activities were 34 people with percentage $51.5 \%$, followed by activities related social 
were 20 people with percentage $30.3 \%$, communication were 9 people with percentage $13.6 \%$, and knowledge were 3 people with percentage $4.5 \%$.

Table 7 Participants based on activities

\begin{tabular}{lcc}
\hline Activities & Frequency & Percent \\
\hline Physical & 34 & 51.5 \\
Communication & 9 & 13.6 \\
Knowledge & 3 & 4.5 \\
Social & 20 & 30.3 \\
\hline Total & 66 & 100 \\
\hline
\end{tabular}

More participants had acute illnesses were 37 people with percentage $56.1 \%$ than participants who had no health problems were 26 people with percentage $39.4 \%$ or had chronic illnesses were 3 people with percentage $4.5 \%$.

Table 8 Participants based on illnesses

\begin{tabular}{lcc}
\hline Illnesses & Frequency & Percent \\
\hline No health & 26 & 39.4 \\
problem & & \\
Acute illnesses & 37 & 56.1 \\
Chronic illnesses & 3 & 4.5 \\
\hline Total & 66 & 100 \\
\hline
\end{tabular}

The majority of the elders feel normal as an elderly group were 36 people with percentage $54.5 \%$, with some reported feeling proud were 16 people with percentage $24.2 \%$ and some reported feeling sad were 14 people with percentage $21.2 \%$.

Table 9 Participants based on feeling

\begin{tabular}{lrc}
\hline Feeling & Frequency & Percent \\
\hline Feeling proud & 16 & 24.2 \\
Feel normal as an & 36 & 54.5 \\
elderly group & & \\
Feeling sad & 14 & 21.2 \\
\hline Total & 66 & 100 \\
\hline
\end{tabular}

Participants who needed assistance were 38 people with a percentage of $57.6 \%$, and participants who did not need assistance were 28 people with a percentage of $42.4 \%$.

Table 10 Participants based on needed assistance

\begin{tabular}{lcc}
$\begin{array}{l}\text { Needed } \\
\text { Assistance }\end{array}$ & Frequency & Percent \\
\hline Yes & 38 & 57.6 \\
No & 28 & 42.4 \\
\hline Total & 66 & 100 \\
\hline
\end{tabular}

Participants who had no hope of any more activities were 3 people with a percentage of $4.5 \%$, participants who stated that they had enough amounted to 47 people with a percentage of $71.2 \%$ and participants who felt they wanted more activities were 16 people with a percentage of $24.2 \%$.
Table 11 Participants based on hope of more activities

\begin{tabular}{lcc}
\hline Hope & Frequency & Percent \\
\hline Had no hope & 3 & 4.5 \\
Had enough & 47 & 71.2 \\
Wanted more & 16 & 24.2 \\
activities & & \\
\hline Total & 66 & 100 \\
\hline
\end{tabular}

The following is a description of the quality of life for young and old (YOLD). Researchers used a measuring instrument totaling 26 items using a scale of 1-5 which has a hypothetical score of 3 and a mean empirical score of 3.9993. This study shows that the empirical mean score is greater than the hypothetical mean, which means that the quality of life of the elderly can be said to be high.

The description of the quality of life of the elderly who are members of the club can be divided into three categories, namely low quality of life for the elderly, average (medium) quality of life for the elderly, and high quality of life for the elderly.

Table 12 Elderly life quality category

\begin{tabular}{lrc}
\hline Category & Frequency & Percent \\
\hline Low & 13 & 19.7 \\
Average & 40 & 60.6 \\
High & 13 & 19.7 \\
\hline Total & 66 & 100 \\
\hline
\end{tabular}

The results of the research regarding the quality of life of elders were that there were no differences in terms of gender, education, ethnicity, income, expenditure, length of joining the elderly club, and their illnesses. However, there is a difference in the quality of life of the elderly in terms of their need for assistance. Elders who need assistance have higher average quality of life $(\mathrm{M}=4.1499)$ than elders who do not need help $(\mathrm{M}=3.7950)$.

Table 13 Differences in the quality of life of the elderly based on the need for assistance

\begin{tabular}{lccc}
\hline $\begin{array}{l}\text { Need for } \\
\text { Assistance }\end{array}$ & Mean & $\mathrm{t}$ & $\mathrm{p}$ \\
\hline Yes & 4.1499 & 2.401 & 0.019 \\
No & 3.7950 & & \\
\hline
\end{tabular}

Likewise, elders' quality of life has differences in terms of their hope and expectations of the elderly. Elders who feel that they have enough activities have a higher quality of life $(\mathrm{M}=2.1489)$ than elders who want to do more activities $(\mathrm{M}=1.5625)$.

Table 14 Differences in the quality of life of the elderly based on the expectations of the elderly in the club

\begin{tabular}{lccc}
\hline Hope & Mean & F & p \\
\hline Had no hope & 2.0000 & 5.906 & 0.004 \\
Had enough & 2.1489 & & \\
Wanted more & 1.5625 & & \\
activities & & & \\
\hline
\end{tabular}


The results of the study are in line with several discussions in the literature review which state that YOLDs can accept the reality to avoid stress, low self-esteem, feel useless, be left out, lonely or that they are prone to disease by having a positive view that old age is an opportunity to develop, showing themselves as people who are active and involved in social activities, which determines a good quality of life and ability to realize the meaning of life. The definition of quality of life put forward by Tonon [1], namely an individual's view of their position in life, in the culture or value system they adopt, related to expectations, interests and achievements. However, The WHOQOL Group [2] also says life is subjective to each individual, in terms of perceiving positive and negative, and is a multidimensional concept.

The overview of the quality of life of young and old (YOLD) elders who are members of elderly clubs in Jakarta are as follows: most participants are from the age group 65-75 years, are female, have an education equivalent to middle school or high school, are of Chinese ethnicity, earning less than IDR 5 million per month and have an expenditure of less than IDR 5 million per month. Furthermore, these seniors have also participated in the elderly club for less than one year, with the types of activities they have participated in are physical or social.

Regarding the illnesses they suffered, elders in this study admitted that they had an acute illness even though there were also some who were chronically ill or did not have any illnesses. They stated that the feeling of being an elder is normal; they feel that there is no difference with the previous period. In addition, they also stated they have achieved enough of what they hoped for in life.

The quality of life of the elders who participated in this club is classified as average or well enough. However, the elderly group who felt that they have enough activities turned out to have a higher quality of life than the group who still expects more activities to be incorporated in the club. In addition, elders who need help or assistance from others have a higher quality of life than the elderly who do not need help.

\section{CONCLUSIONS}

The results of the research regarding the quality of life of elders were that there were no differences in terms of gender, education, ethnicity, income, expenditure, length of joining the elderly club, and their illnesses. However, there is a difference in the quality of life of the elderly in terms of their need for assistance. Elders who need assistance have higher average quality of life $(M=4.1499)$ than elders who do not need help $(M=3.7950)$. Likewise, elders' quality of life has differences in terms of their hope and expectations of the elderly. Elders who feel that they have enough activities have a higher quality of life $(\mathrm{M}=$ 2.1489) than elders who want to do more activities $(\mathrm{M}=$ $1.5625)$.

\section{ACKNOWLEDGMENT}

This work was funded by Institute of Research \& Community Engagement. The researchers are grateful to the Faculty of Psychology, Universitas Tarumanagara especially to the Dean of Psychology who has given the support for this International Collaboration research.

\section{REFERENCES}

[1] S. P, Suardiman, "Psikologi Usia Lanjut," Gadjah Mada University Press. 2011

[2] The Business Standard, "A decade of the Young Old Begins in 2020," https://tbsnews.net/economy/boomersdoing-ok-decade-young-old-begins-2020. 2019

[3] G, Tonon, "Relevance of the use of qualitative methods in the study of quality of life. In G. Tonon (Eds.), Qualitative studies in quality of life: Methodology and practice (pp. 5)," Springer. 2015

[4] The WHOQOL Group, "The World Health Organization quality of life assessment (WHOQOL): Position paper from the World Health Organization," Social Science \& Medicine, 41(10), 1403-1409. 1995.

[5] F. D. Purba, J. A. M. Hunfeld, A. Iskandarsyah, T. S. Fitriana, S. S. Sadarjoen, J. Passchier, \& J. V. Busschbach, "Quality of life of the Indonesian general population: Test-retest reliability and population norms of the EQ-5D-5L and WHOQOL-BREF," PLOS ONE 13(5), e0197098. https://doi.org/10.1371/journal.pone.0197098. 2018. 